\title{
The Impact of the COVID-19 Pandemic on Breast Reconstruction Practices in the United States
}

\author{
WALTER J. JOSEPH, SAMYD S. BUSTOS, JOSEPH E. LOSEE, J. PETER RUBIN and CAROLYN DE LA CRUZ \\ Department of Plastic Surgery, University of Pittsburgh Medical Center (UPMC), Pittsburgh, PA, U.S.A.
}

\begin{abstract}
Background/Aim: We employed a survey to the American Society of Plastic Surgeons (ASPS) to investigate the management of breast reconstruction across the US during the COVID-19 pandemic. Patients and Methods: An electronic survey on breast reconstruction practice demographics, COVID-19-related restrictions on breast reconstruction, and pertinent dates of restrictions was employed. Results: A total of 228 responses were obtained. Demographics were balanced for geography with most respondents located in either urban or suburban settings (91.2\%). The majority proceeded with mastectomy/reconstruction as originally planned (39.0\%), followed by hormonal/chemotherapy only (22.6\%). The most common reconstructive option was tissue expander/implantbased reconstruction (47.7\%). Most institutions implemented restrictions between March 11-20 $0^{\text {th }}$ (59\%). Almost all respondents $(91.8 \%)$ reported mandatory pre-operative SARS Cov-2 testing once cases resumed. Conclusion: COVID-19 has forced the breast surgical team to adapt to new conditions to the detriment of women with breast cancer requiring reconstruction. Varying restrictions have limited access to breast reconstruction, carrying consequences yet to be determined.
\end{abstract}

The COVID-19 pandemic of 2020 has impacted our medical system, and breast surgery was not immune to its effects. This unexpected situation has challenged breast and plastic surgeons, healthcare decision-makers and policy makers, who have been faced with the need to expeditiously

This article is freely accessible online.

This article was previously presented as a meeting abstract at the Virtual Plastic Surgery The Meeting 2020 organized by the American Society of Plastic Surgeons (ASPS).

Correspondence to: Walter J. Joseph, MD, Department of Plastic Surgery, University of Pittsburgh Medical Center, 3550 Terrace Street, 6B Scaife Hall, Pittsburgh, PA 15261, U.S.A. Tel: +1 4123838080, e-mail: josephwj@upmc.edu

Key Words: COVID-19, breast reconstruction, survey. implement containment measures to mitigate the impact of the COVID-19 pandemic. In fact, on March $13^{\text {th }}$, the American College of Surgeons (ACS) recommended that hospitals, health institutions and surgeons across the nation "minimize, postpone or cancel electively schedule operations", some of which included breast reconstruction procedures, in an attempt to maximize bed space, conserve personal protective equipment, and minimize risk of transmission amongst patients and providers (1).

Breast reconstruction is the spectrum of surgical procedures whose aim is to restore the shape of the breast mound after mastectomy in patients with or at risk of breast cancer. Approximately 276,480 new cases of invasive breast cancer will be diagnosed in the United States of America (US) in 2020 (2). Surgery remains the mainstay of breast cancer treatment, and almost half of the patients undergoing mastectomy will be offered breast reconstruction. In 2019 in the US, about 107,238 breast reconstructive procedures were performed, which represents a $5 \%$ increase compared to the number reported in 2018 and a $36 \%$ increment compared to the amount described in 2000 (3). Among the wide range of breast reconstruction procedures, immediate breast reconstruction is on the rise with implant-breast reconstruction (IBR) being the most common method due to the significant advances in support matrices and implants $(4,5)$.

Breast reconstruction has been deemed a woman's right and has been shown repeatedly in the literature to positively impact the quality of life and satisfaction of women diagnosed with breast cancer (6). Remorselessly, the COVID-19 pandemic has stripped women of that right and has undeniably introduced even more fear and apprehension into the already anxiety-provoking scenario of a breast cancer diagnosis. Even though several groups and associations have drafted guidelines or checklists for potential resumption of elective surgeries, little is known on how plastic surgeons across the nation dealt with this new normalcy (7-11).

Consequently, it is of utmost importance to thoroughly study the effect of this pandemic on breast reconstruction practices across the country. As such, we sought to investigate the management of breast cancer and breast 
Table I. Demographics and work practice characteristics of respondents.

\begin{tabular}{|c|c|c|}
\hline Characteristic & Categories & Count (percentage) \\
\hline \multirow{4}{*}{ Region } & Midwest & $43(18.9 \%)$ \\
\hline & Northeast & $39(17.1 \%)$ \\
\hline & South & $85(37.3 \%)$ \\
\hline & West & $61(26.8 \%)$ \\
\hline \multirow[t]{3}{*}{ Type of settlement } & Urban & $107(46.9 \%)$ \\
\hline & Suburban & $101(44.3 \%)$ \\
\hline & Rural & $20(8.8 \%)$ \\
\hline \multirow[t]{9}{*}{ Type of practice } & Academic practice & $29(12.7 \%)$ \\
\hline & Academic practice (salaried with private practice) & $4(1.8 \%)$ \\
\hline & Employed physician & $23(10.1 \%)$ \\
\hline & Large multi-specialty group practice (more than 20 physicians) & $12(5.3 \%)$ \\
\hline & Large plastic surgery group practice (6 or more plastic surgeons) & $7(3.1 \%)$ \\
\hline & Medium multi-specialty group practice (6-20 physicians) & $3(1.3 \%)$ \\
\hline & Small plastic surgery group practice (2-5 plastic surgeons) & $46(20.2 \%)$ \\
\hline & Solo practice & $83(36.4 \%)$ \\
\hline & Solo practice-shared facility & $21(9.2 \%)$ \\
\hline \multirow[t]{5}{*}{ Time spent on type of breast surgery } & Approximately $100 \%$ reconstructive & $29(12.7 \%)$ \\
\hline & Approximately $100 \%$ cosmetic & $6(2.6 \%)$ \\
\hline & Approximately $75 \%$ reconstructive and $25 \%$ cosmetic & $80(35.1 \%)$ \\
\hline & Approximately $75 \%$ cosmetic and $25 \%$ reconstructive & $49(21.5 \%)$ \\
\hline & Approximately $50 \%$ cosmetic and $50 \%$ reconstructive & $64(28.1 \%)$ \\
\hline \multirow[t]{2}{*}{ Perform breast reconstruction in their practice } & Yes & $219(96.1 \%)$ \\
\hline & No & $9(3.9 \%)$ \\
\hline Percentage of breast reconstruction in their practice & & Mean: $42.5 \%$, SEM: $1.9 \%$ \\
\hline
\end{tabular}

SEM: Standard error of the mean.

reconstruction across the US during the time of the COVID19 pandemic to further guide a safe return to offering breast reconstruction.

\section{Patients and Methods}

An exploratory-type survey was constructed to investigate and understand the actions taken by institutions or hospitals across the US in terms of breast reconstruction cases in the setting of the COVID-19 pandemic, the most common strategy of management for breast cancer patients, and an approximate time frame of the operative hiatus. The questionnaire had a cross-sectional, semistructured design and comprised a total of 14 questions. The survey underwent face and content validation by four experts in Registry and Data Analysis of the American Society of Plastic Surgeons (ASPS) and three plastic surgeons at the University of Pittsburgh Medical Center (UPMC) and was distributed electronically by the ASPS Research Services to 2,541 members of ASPS. An initial recruitment email was sent on June $24^{\text {th }}, 2020$, with additional reminders on days 6,16 and 25 after the first recruitment email. The survey was kept open for two weeks after the last reminder email.

Statistical analysis. All statistical analyses were completed using $\mathrm{JMP}^{\circledR}$ Pro 15, SAS (Institute Inc., Cary, NC, 1989-2019). Descriptive statistics including frequency and percentages for categorical variables and means, standard deviations and standard error of means for continuous variables were conducted. Figures and graphics were also obtained from JMP ${ }^{\circledR}$ Pro 15 , SAS. For open- ended questions or open-ended question categories, a content analysis focusing on classifying words or phrases within the text into different content categories was performed. If the new category matched one of the original question options, then it was added into that original category.

\section{Results}

Two hundred and twenty-three members (9.0\%) completed the survey. Table I shows the demographic and work practice characteristics of respondents. Each question was optional, and the number and percentage of responses to each question are also shown in the tables. The majority of respondents were from the South $(n=85,37.3 \%)$, followed by the West $(n=61$, $26.8 \%)$, Midwest $(n=43,18.9 \%)$, and Northeast $(n=39$, $17.1 \%)$. Most respondents worked in either urban $(n=107$, $46.9 \%)$ or suburban areas $(n=101,44.3 \%)$. The majority of surveyed surgeons practiced solo within a shared facility or not $(n=104,45.6 \%)$, followed by small or large plastic surgery group practice $(n=53,23.3 \%)$, academic practice $(n=33$, $14.5 \%)$, employed physician $(n=23,10.1 \%)$, and medium or large multi-specialty group practice $(n=15,6.6 \%)$. A total of $219(96.1 \%)$ respondents mentioned that they perform breast reconstruction in their practice. The average percentage of breast reconstruction in their practice was 42.5\% (SEM: $1.9 \%)$. In regard to the time spent on type of breast surgery, 
Table II. Interventions taken in the setting of the COVID-19 pandemic.

\begin{tabular}{|c|c|c|}
\hline Characteristic & Categories & Count (percentage) \\
\hline \multirow{5}{*}{$\begin{array}{l}\text { Strategy of management for breast } \\
\text { cancer patients at their institution }\end{array}$} & Delay all treatment & $14(7.2 \%)$ \\
\hline & Proceed with hormone/chemotherapy alone & $44(22.6 \%)$ \\
\hline & Proceed with mastectomy without reconstruction & $28(14.4 \%)$ \\
\hline & Proceed with mastectomy with reconstruction as originally planned & $76(39.0 \%)$ \\
\hline & Other & $33(16.9 \%)$ \\
\hline \multirow[t]{7}{*}{$\begin{array}{l}\text { Actions undertaken in terms of breast } \\
\text { reconstruction cases at their institution }\end{array}$} & $\begin{array}{l}\text { No breast surgery (including oncologic) at all; } \\
\text { only medical/nonsurgical treatment allowed }\end{array}$ & $31(15.9 \%)$ \\
\hline & No immediate breast reconstruction at all & $37(19.0 \%)$ \\
\hline & $\begin{array}{l}\text { Only tissue expander/implant-based breast reconstruction } \\
\text { allowed (no autologous/free flap breast reconstruction allowed) }\end{array}$ & $93(47.7 \%)$ \\
\hline & $\begin{array}{l}\text { No delayed procedures (only immediate implant-based } \\
\text { or immediate autologous breast reconstruction) }\end{array}$ & $9(4.6 \%)$ \\
\hline & No restrictions & $15(11.6 \%)$ \\
\hline & Entire facility shutdown & $2(1.0 \%)$ \\
\hline & Other & $8(4.1 \%)$ \\
\hline \multirow{5}{*}{$\begin{array}{l}\text { Level of agreement to the following statement: } \\
\text { "I believe my hospital/institution policies were } \\
\text { appropriate regarding breast reconstruction in } \\
\text { the setting of the COVID-19 pandemic" }\end{array}$} & Strongly agree & $85(43.6 \%)$ \\
\hline & Agree & $74(38.0 \%)$ \\
\hline & Neutral & $14(7.2 \%)$ \\
\hline & Disagree & $17(8.7 \%)$ \\
\hline & Strongly disagree & $5(2.6 \%)$ \\
\hline
\end{tabular}

$109(47.8 \%)$ answered it was mostly reconstructive, 55 (24.1\%) mentioned it was mostly cosmetic, and 64 (28.1\%) answered that both types, reconstructive and cosmetic breast surgeries, weighted almost equally in their practice.

Interventions taken by the institutions in the setting of the COVID-19 pandemic are shown in Table II. Regarding the management of breast cancer, most institutions proceeded with mastectomy as originally planned $(n=76,39.0 \%)$. However, a combined $44.2 \%$ of respondents $(n=86)$ reported that, in some capacity, reconstruction was not considered a part of the treatment algorithm (Delay all treatment $=7.2 \%$; Hormone/ Chemotherapy alone $=22.6 \%$; Mastectomy without reconstruction $=14.4 \%)$. Ninety-three surgeons (47.7\%) responded that their institutions or hospitals restricted their breast reconstruction only to tissue expander or implant-based breast reconstruction (no autologous breast reconstruction was allowed). The next most common intervention was no immediate breast reconstruction at all $(n=37,19.0 \%)$, followed by no breast surgery at all $(\mathrm{n}=31,15.9 \%)$, and no restrictions $(\mathrm{n}=15,11.6 \%)$. Almost all $(91.8 \%)$ required mandatory preoperative testing for resumption of surgeries. A total of 159 $(81.6 \%)$ respondents agreed or strongly agreed with the policies instated by their institution regarding breast reconstruction in the setting of the COVID-19 pandemic (Table II). On the other hand, only $22(11.3 \%)$ respondents disagreed or strongly disagreed with the appropriateness of the policies established by their institutions.

Figures 1 and 2 depict the dates when restrictions were instated and surgeries were resumed or ban was lifted, respectively, compared to national trends. Most institutions $(n=113,59 \%)$ established some type of restriction between March $11^{\text {th }}$ and March $20^{\text {th }}$. Resumption of breast reconstruction surgeries or lift of restrictions occurred mostly between May $1^{\text {st }}$ and May $10^{\text {th }}(\mathrm{n}=41,21 \%)$, followed by May $11^{\text {th }}$ and May $20^{\text {th }}(\mathrm{n}=35,18 \%)$ and June $1^{\text {st }}$ to June $10^{\text {th }}$ $(\mathrm{n}=29,15 \%)$. Of note, $21(11 \%)$ surgeons answered that a date to resume breast reconstruction is still to be determined.

\section{Discussion}

The COVID-19 pandemic has changed the landscape of medicine, as we once knew it. Breast and plastic surgeons across the US could have never predicted that elective surgeries would be cancelled and surgery centers would close down at the hands of a virus. We could have never predicted that something so fundamental as a woman's right to breast reconstruction after mastectomy would be in jeopardy. Over the course of the pandemic, thousands of women in the US were diagnosed with breast cancer, many of whom were forced to delay or even forego their breast reconstruction. And along with these women who were dealt this misfortune, their plastic surgeons, too, were left to make decisions that often diverted from their typical practices for the sake of their patients' safety. As such, we thought it would be of paramount importance to deconstruct the effect that the COVID-19 pandemic has had on breast reconstruction practices across the US and how those effects would vary by geographic region and practice type. 


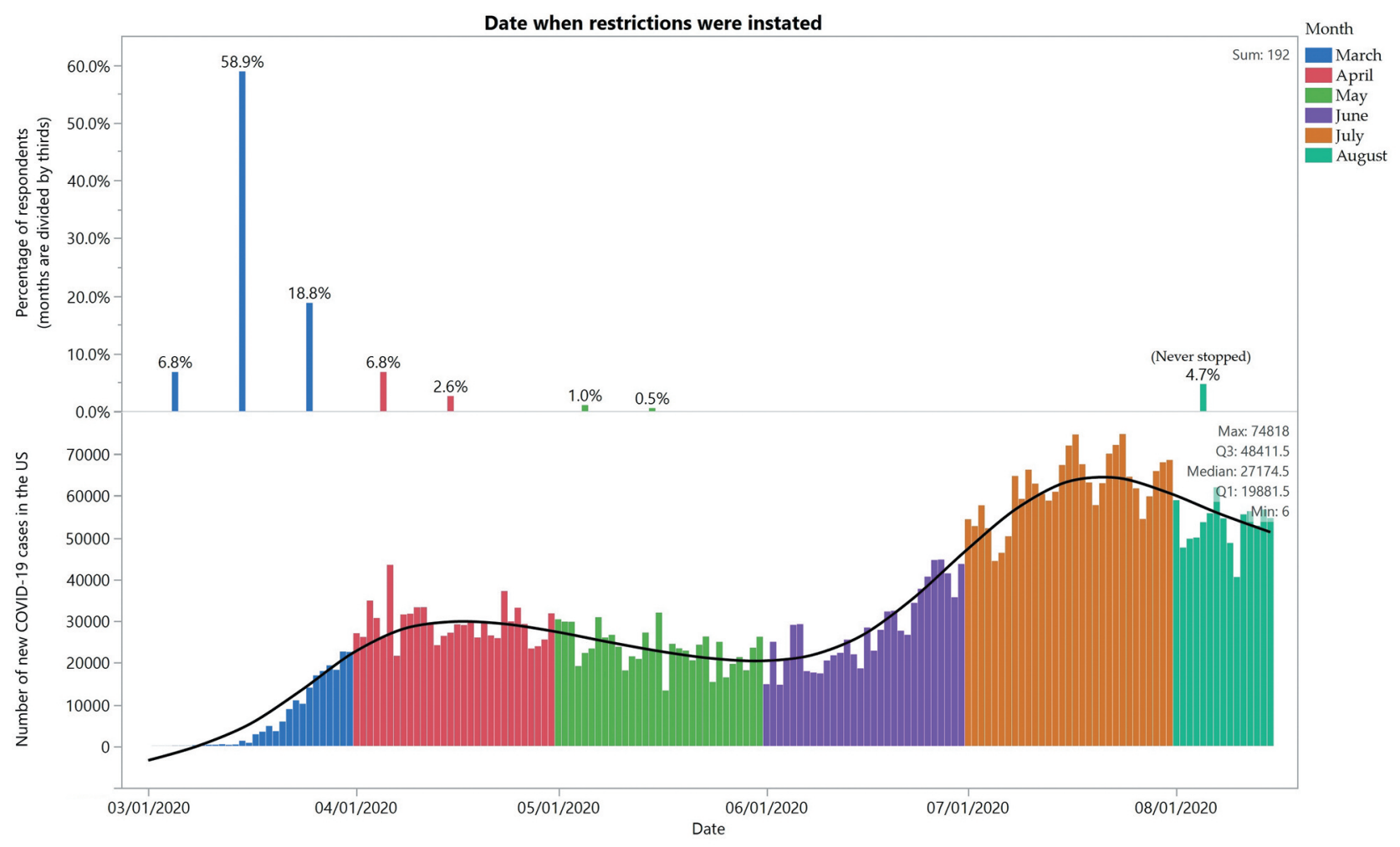

Figure 1. Date when restrictions on breast reconstruction surgeries were instated compared to national trends.

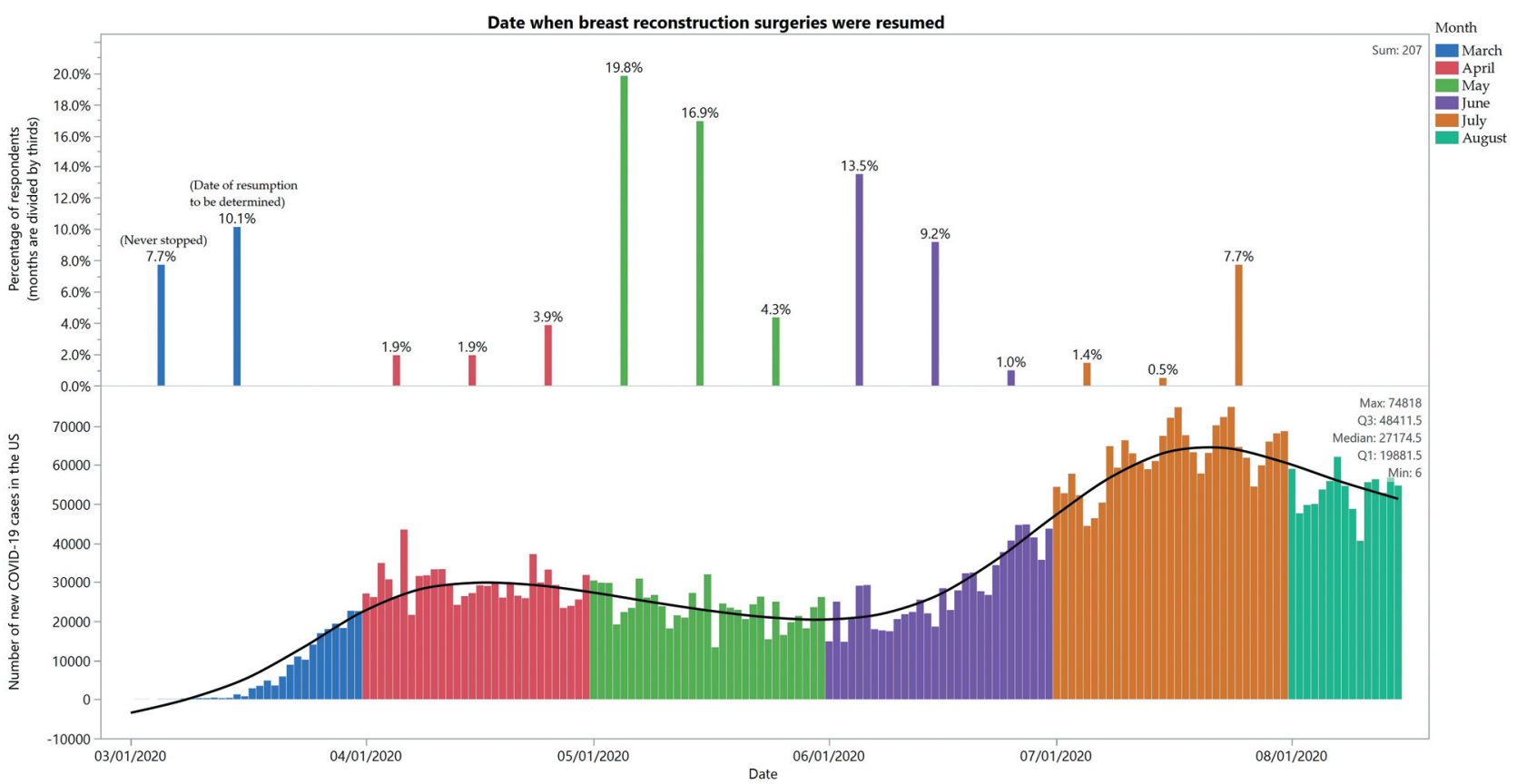

Figure 2. Date when breast reconstruction surgeries were resumed or ban was lifted compared to national trends. 
To date, our study on COVID-19 and our survey data represent the largest cohort of responses pertaining to a specific set of procedures from the largest plastic surgery society in our country, the ASPS. Of note, the ASPS represents a broad spectrum of practices among Board Certified plastic surgeons, providing a realistic and accurate representation of plastic surgeons in the US. Strikingly, nearly half $(44.2 \%)$ of the responders indicated that breast reconstruction - in any capacity - was not occurring at their institutions during the pandemic, whether that was via delay of all oncologic treatment, hormone/chemotherapy alone, or mastectomy alone. It remains to be seen whether or not this aberration from standard treatment protocols will have an effect on future oncologic outcomes for these patients.

Our data show that a majority $(58.9 \%)$ of surgeons reported that restrictions on surgeries performed at their respective institutions were instated during the middle third of the month of March, which appropriately corresponds to the rising number of cases across the US (Figure 1). Temporally, this also corresponds with the ACS Statement on Recommendations for Management of Elective Procedures on March $13^{\text {th }}, 2020$, and with the ASPS Statement on Breast Reconstruction in the face of the COVID-19 Pandemic issued on March $24^{\text {th }}, 2020$, which encouraged delayed reconstruction, advised against any autologous reconstruction, and recommended that implant-based reconstruction be examined on a case-by-case basis $(1,12)$. In an ACAPS survey study by Sarac et al., 95\% of their respondents reported adhering to the ASPS recommendations, unless otherwise guided by direct state or intuitional policies (7). Interestingly, academic practices had the highest percentage of restrictions instated as late as April (16.7\%). Furthermore, on approximately April $6^{\text {th }}$, the US number cases of COVID-19 had reached an initial peak, and at this point in time, $93.9 \%$ of plastic surgeons reported that restrictions had been instated. Cases across the United States remained relatively high throughout the month of April as much of the country attempted to "flatten the curve." Over this time, at institutions where breast reconstruction after mastectomy was permitted, immediate implant-based reconstruction was the most common practice reported among plastic surgeons $(47.7 \%)$. This finding is consistent with other recent studies $(7,11,13)$.

It was not until the beginning of May that case numbers began to fall, and as such, we found that during the first third of May, a majority (19.8\%) of plastic surgeons reported that the restrictions at their institutions had been lifted (Figure 2). When these data were broken down by geographic region, a vast majority of the practices in the South and West were more aggressive with their re-openings (majority in May), whereas in the Northeast and the Midwest, a more conservative approach to re-opening was taken and the lifting of restrictions was more likely to occur in June.

Despite such variation in approaches taken by different institutions across the country, an overwhelming majority of plastic surgeons $(81.6 \%)$ responded that they either agreed or strongly agreed with their respective institutions policies. Nonetheless, $11.3 \%$ either disagreed or strongly disagreed. In a published commentary by Kumar et al., the authors assert that immediate autologous reconstruction was unfairly restricted, citing the inherent decreased infection risk, in-person office visits, and overall increased psychosocial satisfaction as compared with implant-based reconstruction (14).

While our study examined the effects of the COVID-19 pandemic on breast reconstruction practices across the country, the study was limited in its ability to highlight the impact on the patients themselves. In future studies, we hope to examine the cohort of patients at our institution whose breast cancer care was affected by COVID-19 and prospectively follow both their oncologic and reconstructive outcomes. We also plan on using the BREAST-Q to assess the psychosocial effect on these patients with COVID-19 as an added variable in their treatment course. Lastly, due to the timing of survey distribution, our study did not fully delineate the impact of the 2 nd rise in COVID-19 cases observed from mid-July.

In conclusion, despite the geographic variability in case numbers, breast and plastic surgeons across our nation were forced to modify their breast reconstruction practices in order to conserve personal protective equipment, protect our healthcare workers, protect themselves, and protect their patients. Many surgeons reported a complete hiatus of both surgical oncologic treatment and reconstructive procedures. Overall, institutional restrictions appropriately correlated with rising case numbers, and subsequently, resumption of cases was appropriately timed with a down-slope in the case curve. An overwhelming majority of respondents were satisfied with the institutional actions taken in regard to the practice of breast reconstruction.

\section{Conflicts of Interest}

The Authors declare no commercial associations or financial disclosures that might pose or create a conflict of interest with information presented in this manuscript.

\section{Authors' Contributions}

All Authors contributed to the study design, commented on previous versions of the manuscript, read and approved the final manuscript. Material preparation, data collection and analysis were performed by CDLC, WJJ and SSB. The first draft of the manuscript was written by WJJ and SSB.

\section{Acknowledgements}

The study was funded by the Department of Plastic Surgery, University of Pittsburgh Medical Center (UPMC), Pittsburgh, Pennsylvania, U.S.A. 


\section{References}

1 COVID-19: Recommendations for management of elective surgical procedures (2020). Available at: https:/ /www.facs.org/covid-19/clinical-guidance/elective-surgery [Last accessed on September 8, 2020]

2 How common is breast cancer? (2020). Available at: https://www.cancer.org/cancer/breast-cancer/about/howcommon-is-breast-cancer.html [Last accessed on September 8, 2020]

3 Plastic Surgery Statistics Report: ASPS National Clearinghouse of Plastic Surgery Procedural Statistics. (2019). Available at: https://www.plasticsurgery.org/documents/News/Statistics/2019/ plastic-surgery-statistics-full-report-2019.pdf [Last accessed on September 8, 2020]

4 Albornoz CR, Bach PB, Mehrara BJ, Disa JJ, Pusic AL, McCarthy CM, Cordeiro PG and Matros E: A paradigm shift in U.S. Breast reconstruction: increasing implant rates. Plast Reconstr Surg 131(1): 15-23, 2013. PMID: 23271515. DOI: 10.1097/PRS.0b013e3182729cde

5 Jagsi R, Jiang J, Momoh AO, Alderman A, Giordano SH, Buchholz TA, Kronowitz SJ and Smith BD: Trends and variation in use of breast reconstruction in patients with breast cancer undergoing mastectomy in the United States. J Clin Oncol 32(9): 919-926, 2014. PMID: 24550418. DOI: 10.1200/JCO.2013.52.2284

6 Yueh JH, Slavin SA, Adesiyun T, Nyame TT, Gautam S, Morris DJ, Tobias AM and Lee BT: Patient satisfaction in postmastectomy breast reconstruction: a comparative evaluation of DIEP, TRAM, latissimus flap, and implant techniques. Plast Reconstr Surg 125(6): 1585-1595, 2010. PMID: 20517080. DOI: 10.1097/PRS.0b013e3181cb6351

7 Sarac BA, Schoenbrunner AR, Wilson SC, Chiu ES and Janis JE: The impact of COVID-19-based suspension of surgeries on plastic surgery practices: A survey of acaps members. Plast Reconstr Surg Glob Open 8(8): e3119, 2020. PMID: 32983820. DOI: $10.1097 / G O X .0000000000003119$
8 Bustos SS, Bustos VP and Nguyen MT: Elective surgery in asymptomatic patients with undetected SARS-CoV-2 infection: lessons learned from the global operating room. Br J Surg 107(10): e399-e400, 2020. PMID: 33448340. DOI: 10.1002/bjs.11843

9 Considerations for the Resumption of Elective Surgery and Visits: ASPS Statement. (2020) Available at: https://www.plasticsurgery. org/for-medical-professionals/covid19-member-resources/ resumption-of-elective-surgery [Last accessed on September 9, 2020]

10 American College of Surgeons Post-COVID-19 Readiness Checklist for Resuming Surgery. (2020). Available at: https://www.facs.org/covid-19/checklist [Last accessed on September 10, 2020]

11 Vidya R, Rubio IT, Paulinelli RR, Rancati A, KolacinskaVoytkuv A, Salgarello $M$ and Becker H: Should breast reconstruction and breast oncoplastic procedures be performed during the coronavirus pandemic? Ecancermedicalscience 14: 1041, 2020. PMID: 32565894. DOI: 10.3332/ecancer.2020.1041

12 ASPS Statement on Breast Reconstruction in the face of COVID-19 Pandemic (2020). Available at: https:// www.plasticsurgery.org/documents/medical-professionals/ COVID19-Breast-Reconstruction-Statement.pdf [Last accessed on September 10, 2020]

13 Chetta MD, Schoenbrunner AR and Lee CN: Postmastectomy Breast Reconstruction in the Time of the Novel Coronavirus Disease 2019 (COVID-19) Pandemic. Plast Reconstr Surg Glob Open 8(6): e2967, 2020. PMID: 32766087. DOI: 10.1097/GOX.0000000000002967

14 Ganesh Kumar N and Kung TA: Guidelines for breast reconstruction during the COVID-19 pandemic: Are we considering enough evidence? Breast J 26(10): 2108-2109, 2020. PMID: 32794328. DOI: 10.1111/tbj.14015

Received January 24, 2021

Revised February 1, 2021

Accepted February 2, 2021 